\title{
Peripheral Sensitivity to Steroids Revisited
}

\author{
R. HAMPL ${ }^{1}$, K. VONDRA ${ }^{1}$ \\ ${ }^{1}$ Institute of Endocrinology, Prague, Czech Republic
}

Received May 24, 2017

Accepted May 31, 2017

\section{Summary}

Resistance to steroid hormones presents a serious problem with respect to their mass use in therapy. It may be caused genetically by mutation of genes involved in hormonal signaling, not only steroid receptors, but also other players in the signaling cascade as co-regulators and other nuclear factors, mediating the hormone-born signal. Another possibility is acquired resistance which may develop under long-term steroid treatment, of which a particular case is down regulation of the receptors. In the review recent knowledge is summarized on the mechanism of main steroid hormone action, pointing to already proven or potential sites causing steroid resistance. We have attempted to address following questions: 1) What does stay behind differences among patients as to their response to the (anti)steroid treatment? 2) Why do various tissues/cells respond differently to the same steroid hormone though they contain the same receptors? 3) Are such differences genetically dependent? The main attention was devoted to glucocorticoids as the most frequently used steroid therapeutics. Further, androgen insensitivity is discussed with a particular attention to acquired resistance to androgen deprivation therapy of prostate cancer. Finally the potential causes are outlined of breast and related cancer(s) resistance to antiestrogen therapy.

\section{Key words}

Steroid hormone • Glucocorticoid • Androgen • Estrogen • Receptor • Resistance

\section{Corresponding author}

R. Hampl, Institute of Endocrinology, Národní 8, 11694 Prague 1, Czech Republic. E-mail: rhampl@endo.cz

\section{Introduction}

Physicians using steroid hormone and their synthetic analogues for therapy know well that there are large differences among patients as to their response to the treatment. The most frequent questions are: 1) What does stay behind these differences? 2) Why do various tissues/cells respond differently to the same steroid hormone though they contain the same receptors? 3) Are such differences genetically dependent?

Various cell types differ as to expression (transactivation/transrepression) of genes which are under control of steroid hormone or its agonist. Moreover, various mechanisms are employed here depending on the composition of the gene promotor region governing the response to steroid-receptor binding. Finally the receptors themselves, though products of one gene, exist in various isoforms due to their posttranscriptional modifications.

Generally, altered sensitivity to (steroid) hormones may be caused: 1) Genetically, by changes in the steroid receptor gene or in the other transcription factors responsible for hormone-bearing signal, similarly as in other receptor superfamily (thyroid hormone-, D-vitamin-, retinoid receptors). 2) By changed steroid signal transduction. The especial case of both latter events is steroid receptor down regulation. 3) By altered function of controlling steroid hormone production on the central level (hypothalamo-pituitary-glandular axes) or those influencing the local steroid production (cytokines etc.). 4) By changing of bioavailability of the hormone in the target cells. In the following text we will attempt to provide a survey of recent knowledge addressing these topics. 


\section{Glucocorticoids}

Most studies looking for the cause of altered sensitivity to steroids have been dealing with glucocorticoids (GC) with respect to their large use as therapeutics. Natural as well as synthetic glucocorticoids have been using as immunosuppressive, antiinflammatory, antialergic agents since the end of World War II, but as late as within the last decades the molecular mechanisms staying behind these effects have been elucidated. In addition, glucocorticoids are known as stress hormones, acting as the slower partners of catecholamines in response to stress. It was estimated that up to $20 \%$ of expressed genes are positively or negatively regulated by glucocorticoids (Cain and Cidlowski 2015). It is also known that effects of GC differ between males and females. The molecular basis of this sexual dimorphism is still unknown and requires further research (Quinn et al. 2014).

\section{The mechanisms of genomic glucocorticoid action}

The mechanisms consisting in controlling gene expression (activation or repression) have been comprehensively reviewed by Cidlowski group (Schaaf and Cidlowski 2002, Zhou and Cidlowski 2005). In brief, a glucocortiod after free passage across the cell membrane binds to its cytoplasmatic receptor, which in turn undergoes conformational changes and splitting of chaperonic heat shock protein, enabling to bind through its DNA binding domain to hormone responsive elements (HRE, GRE) of the promoter region (but not identical with) of the controlled gene. Usually two glucocortioidreceptor complexes are bound to two not neighboring GREs leading to enhancement of hormone signal. The binding of steroid-receptor complex to the GRE initiates a formation of an assembly of nuclear transcription factors the cross-talk of which function as a bridge between the s.c. transactivation ( $\mathrm{N}$-terminal) domain of the receptor and the gene initiation site, making its accessible to mRNA polymerase. Recent studies revealed that GC-activated glucocorticoid receptor (GR) cannot only bind directly to GRE (including negative, nGRE), but instead to GRE interact with the key transcription factors, staying at the first place of the assembly of nuclear transcription factors and thus modulate GC-induced signaling, resulting in transcription induction or repression of the controlled gene. Activation protein A (AP-1) and nuclear factor- $\mathrm{\kappa B}(\mathrm{NF}-\mathrm{\kappa B})$ are such well known factors. Morover, a composite mechanism consisting in a simultaneous action of both latter may occur (Cain and Cidlowski 2015).

It should be mentioned, though the mechanism of glucocorticoid action including signaling pathways seems to be very complicated and involves a plethora of factors, many of them are of a common use, possess many functions and participate at various physiological processes. Examples are enzymes phoshorylating steroid receptors and other members in the signaling cascades leading to gene activation/repression, which are the same well known kinases involved in various biochemical reactions (e.g. glycogen synthase phosphorylase). Heat shock proteins (hsp) associated with GR the dissociation of which is a part of activation process, are abundant proteins in the cell, serving as chaperones and protect cells from stress. Transcription factors as already mentioned AP-1 posses many functions in signaling pathways (Schaaf and Cidlowski 2002).

Possible sites responsible for altered sensitivity/ resistance to $G C$

It is evident from this outline that there are several steps/sites which may be responsible for modulation of the response to a hormone, leading to a changed sensitivity: the character of the receptor and the quality and availability of transcription factors, all of which may be also genetically conditioned. Experiments from the last decades brought detailed information of the structure of the GR and its gene. All three domains of the receptor-ligand binding, DNA binding and transactivation domain from animals and humans were characterized and compared with other hormonal receptors as to their conservativeness. Gene constructs were prepared for studies of their role in hormone action. Among the findings of particular interest is existence of multiple human GR isoforms from a single gene arising from alternative splicing and alternate translation initiation sites (hGR $\alpha, \mathrm{hGR} \beta, \mathrm{hGR} \gamma$ ), which is tissue specific and may explain different response there (Zhou and Cidlowski 2005, Cain and Cidlowski 2015). In addition, the GR may undergo posttranslational modifications such as phosphorylation, ubiquitination, acetylation or sumoylation (Cain and Cidlowski 2015, Hua et al. 2016).

\section{Down regulation of $G R$}

Reduced sensitivity to GC may be caused by down regulation of GRs. Schaaf and Cidlowski (2002) defined three possible mechanisms responsible for this 
phenomenon: 1) Activation of negative GRE (nGRE) in the promotor region of GR resulting in its transcription repression. 2) Alternative splicing and overproduction of GR- $\beta$ isoform. GR- $\beta$ does not bind ligand, cannot transactivate gene transcription, but can bind to GRE. 3) Repression by already mentioned transcription factor $\mathrm{NF}-\kappa \mathrm{B}$, due to mutual antagonism between the latter and GR. Another cause (as described in rats) can be decreased GR mRNA expression following stress induced increase of GC by multiple other molecular mechanisms including increased DNA methylation of GR gene (Mifsud et al. 2017).

Genetic factors as predisposition of glucocorticoid resistance or hypersensitivity

It is not surprising that the first reason of altered glucocorticoid sensitivity as demonstrated by resistance or hypersensitivity was searched in mutations of GR gene (NR3C1). However, the recent research revealed that generalized resistance to GC due to GR mutations, known as Chrousos syndrome, is relatively rare condition, in contrast to plethora of GR splicing variants (Liang et al. 2016). A systematic search in the literature concerning inactivating mutations, insertions or deletions in the human glucocorticoid receptor (hGR) gene (NR3C1) has been performed by Greek authors who summarized until now described GR gene mutations (Charmandari 2012, Nicolaides and Charmandari 2015, Nicolaides et al. 2016a,b). Recent elucidation of the mechanisms involved in GC action, as outlined in previous paragraph, pointed to the role of transcription factors/coactivators (Luca et al. 2013, Nicolaides et al. 2014), the genetic mutations of which may occur as well, and new findings may be expected soon.

Regulation of glucocorticoid biosynthesis and its metabolism in target cells

Adrenal biosynthesis of $\mathrm{GC}$ is regulated by hypothalamo-pituitary-adrenal axis involving classic negative feed-back loop on both pituitary and hypothalamic sites secerning corticoliberin $(\mathrm{CRH})$ and adrenocorticotopin (ACTH) respectively. The release of $\mathrm{CRH}$ and ACTH is also influenced by neural and humoral signals, in the latter case by various cytokines (Cain and Cidlowski 2015). Of interest may be recent finding that certain tissues as e.g. skin possess an autonomous regulating system including $\mathrm{CRH}$, proopiomelanocortin (a precursor of ACTH) and their receptors, parallel with HPA axis (Slominski et al. 2015).
Sensitivity to GC may be also influenced by their availability in target cells by a ubiquitous enzyme

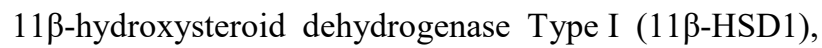
maintaining balance between biologically active cortisol and inactive cortisone. Polymorphic variants of the enzyme in clinical diseases were described and downregulation of the gene expression is a typical feature of the development of colorectal polypous lesions and their transformation into colorectal adenocarcinoma (Cooper and Stewart 2009). 7-oxygenated metabolites of dehydroepiandrosterone (DHEA), 7-oxo-DHEA, $7 \alpha$-hydroxy-DHEA and its $7 \beta$-hydroxy-isomer, suggested as possible treatment of excessive actions of glucocorticoid, were shown to compete for this enzyme (Hennebert et al. 2007). The potential significance of local endogenous GC concentration appears to be an important anti-inflammatory response that protects against inflammatory muscle wasting caused by long-term glucocorticoid treatment.

\section{Practical impacts}

Elucidation of molecular mechanism of GC action and altered sensitivity has got a prominent importance for their use in therapy of a wide range of inflammatory, autoimmune and other disorders, including neurodegenerative diseases such as multiple sclerosis, parkinsonism or even Alzheimer dementia. Their immunosuppressive properties are employed for preventing of organ rejection in transplantation. GC have been using for treatment of hematological malignancies as lymphomas, myelomas and leukemias for their lympholytic effects. GC, synthetic or natural are applied systemically as well as locally.

Major problems the physicians encounter when using GC treatment are the following:

1) How to minimize their numerous harmful side effects. Let's mention here the most serious ones: HPA dysfunction, impairment of glycoregulation leading to diabetes, hypertension, both latter resulting in development of metabolic syndrome, osteopenia/ osteoporosis, muscle and skin atrophy, worsening of wound healing, water and electrolyte dysbalance, development of peptic ulcers, cataract, mycoses, thromboembolic disease, depression or even psychoses, and generally increased predisposition to infections. Well known are the effects of glucocorticoids on proliferation, differentiation and apoptosis where GC have been identified to play a role in pathogenesis and the development of various cancers. The consequences of 
long-term GC therapy depend to a large extent on the total cumulative dose, an application form and the type of the drug.

2) Targeting the therapy to the diseased organs/ cells.

3) How to overcome the resistance to GC either inborn (genetically conditioned) or acquired. In all instances the interindividual differences among patients should be considered, so that ideal is a personal, tailor made therapy.

Several ways are currently investigated to overcome these problems as follows: Search for synthetic GC-analogues which would selectively drive the GC-GR signaling. An example may be ligands which would bind to GR and trigger GR-protein interaction, but without binding of GC-GR complex to DNA. Such selective GR agonists/antagonists could be used in repression of inflammatory transcription factors (Cain and Cidlowski 2015). Attempts were undertaken to influence pharmacologically the expression of GR- $\alpha$ on account of its GR- $\beta$ isoform. Methotrexate (a chemotherapy agent and immune system suppressant) has been used for this purpose (Goecke et al. 2007). So far hypothetic but promising would be targeted intervention into GC signaling focused on unveiled role of co-activators and transcription factors. It concerns especially the AP-1 and NF- $\kappa \mathrm{B}$ signaling. Another possibility consists in modulation (inhibition or stimulation) of enzymes responsible for local GC availability (Cooper and Stewart 2009).

\section{Sex hormones 1: androgens}

From the clinical point of view a serious problem is androgen deficiency with its different impact on men and women, which may in some instances resemble features of androgen resistance. These topics would by far exceed the scope of this paper, which is androgen resistance.

Two major clinical situations are associated with impaired sensitivity to androgens: 1) Pathologies caused by mutation of androgen receptor (AR), of which the most important are androgen insensitivity syndrome (AIS) and (secondly) spinal and bulbar muscular atrophy known as Kennedy disease (Poletti et al. 2005). 2) Acquired or later developed resistance to antiandrogen or androgen depletion therapy in castration resistant prostate, eventually other cancers (Karantanos et al. 2015, Wadosky and Koochekpour 2016). While the former fully depends on androgen receptor itself its isoforms and splicing variants, the latter depends not only on the quality of AR, but also on other events related to androgen-triggered signaling.

\section{Androgen receptor and signaling}

Androgen receptor and its gene have been characterized as early in 1988 (Trapman et al. 1988). The gene NCR3C4 is localized on the $\mathrm{Xq}$ arm of the $\mathrm{X}$ chromosome and the protein exists in several splicing variants and binds both testosterone and dihydrotestosterone (Antonarakis et al. 2016). As other receptors of this family it consists of ligand binding-, DNA binding- and transactivation domains, differing in their conservativeness. Its mechanism of action is the same as for other steroid hormones as described above for glucocorticoids, the signaling pathway includes interaction of activated androgen receptors with other nuclear transcription factors resulting in up- or downregulation of specific gene transcription (Heemers and Tindall 2007, Heinlein and Chang 2016).

\section{Androgen insensitivity syndrome (AIS)}

The severity of androgen insensivity is usually classified as mild- (MAIS), partial- (PAIS), or complete insensitivity syndrome known as testicular feminization (CAIS). They are present as phenotypes associated with complete or partial resistance to the action of androgens, between which exists multifarious scale of clinical variants. We will not describe here either the management or treatment of its clinical forms, which are subject of many reviews (Mongan et al. 2015, Hiort 2013, Hughes et al. 2012). Indeed, thousands of original papers and hundreds of reviews can be found in PubMed under the key words "androgen resistance" or "androgen insensitivity".

Generally, androgen insensitivity is caused by non-functional or partially functional androgen receptor. In contrast to glucocorticoid receptor, hundreds of mutations of AR gene were described up-to-now, which need not always correlate with the clinical picture and many of them are very rare. For instance Brinkmann in his review (2001) refers about 150 mutations, while eleven years later Hughes et al. (2012) mention more than 800 mutations. A database of AR mutations has been set up and is being currently refilled (www.androgendb.mcgill.ca/). In this review we attempted to summarize briefly only the up-to-date major molecular and genetic basis of this syndrome as follows: 1) As other steroid receptors, the AR acts in concert with 
an array of so far only partly known cofactors/transition factors which modulate target gene transcription or repression (Hiort 2013). Involvement of the AR associated proteins as contributors to partial androgen insensitivity belongs to a live area of research (Mongan et al. 2015). 2) The androgen signaling pathways are complex, but so far the only gene linked with AIS is the androgen receptor itself (Jääskeläinen 2012). 3) Though mutations were described throughout the whole gene, a preponderance is located in the ligand binding domain (Hughes et al. 2012). 4) Numerous genetic defects in the AR, leading to distinct types of genetic alterations and identified in various segments of the AR gene are invariably associated with complete androgen insensitivity phenotype, while mutations that cause single amino acid substitution within the AR protein are localized in the DNA- or ligand binding domains and manifest themselves as a wide range of androgen resistant phenotypes (McPhaul 2002). 5) In contrast to GR, relatively little is known so far of (already mentioned) co-regulators and co-activators (Heemers and Tindall 2007, Culig and Santer 2012), AR splicing variants (Nakazawa et al. 2014) or its posttranslational modifications (Koryakina et al. 2014).

\section{Spinal and bulbar muscular atrophy (SBMA)}

This is another disorder caused by AR gene mutation. It is also known as Kennedy's disease characterized by slowly progressive muscle weakness and atrophy of the bulbar, facial and limb muscles and associated with motor neuron loss in the spinal cord and brain stem (Fischbeck 2016). In contrast to hundreds of mutations described for AIS, it is caused only by expansion of a CAG trinucleotide repeat sequence in exon 1 of the AR gene encoding a polyglutamine (polyQ) tract. It is a rare, adult-onset, X-linked recessive neuromuscular disease. A typical feature of SBMA is sex specificity since SBMA fully manifests only in males. The most frequent systemic symptom is gynecomastia (Pennuto and Basso 2016, Querin et al. 2017). An insight into the molecular signaling, namely an interdomain interaction of the AR within the nucleus, which is required for $\mathrm{AR}$ aggregation and toxicity, enabled to suggest ligands preventing this interaction and may be promising for treatment (Orr et al. 2010).

Resistance to antiandrogen or androgen depletion therapy in castration resistant prostate cancer (CRPC)

Common experience shows that many patients with a prostate cancer under antiandrogen or androgen depletion therapy including castration develop after several (2-3) years resistant cancer, associated with restored androgen signaling. Even use of novel endocrine therapies indicated that CRPCs remain androgensensitive (Tan et al. 2012). Genetic mutations of AR gene were therefore searched in these patients. Though they are relatively rare in untreated prostate cancers, they have been found in CRPCs. Discovered AR aberrations include amplification of the AR gene leading to the over expression of the receptor as well as point mutations of AR and formation of active AR splice variants (Waltering et al. 2012, Nakazawa et al. 2014, Koryakina et al. 2014). Attention was further turned to the role of individual players involved in androgen signaling as coregulators and coactivators (Culig and Santer 2012) as well as postranslational modifications (Karantos et al. 2015). A universal mechanism, by which prostatic cancer becomes resistant to therapy, if any, however remains yet to be discovered. Reviews addressing these issues have been published recently summarizing so far known molecular mechanisms by which prostate cancer evades androgen deprivation therapy, including novel ways of treatment targeting on various factors involved in AR molecular signaling (Wadosky and Koochekpour 2016, Boudadi and Antonarakis 2016).

\section{Sex hormones 2: estrogens}

An absolute majority of studies concerning impaired sensitivity or resistance to estrogens concern breast and related cancers. More than 30,000 of original papers and more than 4,000 reviews addressing this issue can be traced in the PubMed database, including numerous meta-analyses. Here we will mention only a few recent reviews, of which the reader may gain basic information on recent findings and trends of the topics.

\section{Breast and related cancer(s) and estrogen resistance}

About one fourth of patients with primarily detected breast cancer are resistant to endocrine treatment consisting usually of a combination of antiestrogens and aromatase inhibitors. More than $70 \%$ of them and almost all patients with metastases evolve later resistance to the therapy (Jeselsohn et al. 2015, Jeselsohn et al. 2017, Clarke et al. 2015, Kerdivel et al. 2013). The search trying to explain this phenomenon focused at first on the quality and function of estrogen receptors (ER). 


\section{Estrogen receptors and signaling}

Two different isoforms of the estrogen receptor exist, usually referred to as $\alpha$ and $\beta$, each encoded by a separate genes ESR1 and ESR2, respectively. Hormoneactivated estrogen receptors form dimers, and, since the two forms may be coexpressed, the receptors may form $\operatorname{ER} \alpha(\alpha \alpha)$ or $\operatorname{ER} \beta(\beta \beta)$ homodimers or $\operatorname{ER} \alpha \beta(\alpha \beta)$ heterodimers (Li et al. 2004). The mutations of ER $\alpha$ accounting for primary estrogen resistance are relatively rare (Jeselsohn et al. 2015, Thomas and Gustafsson 2015). These mutations are located within the ligandbinding domain of the ER and lead to ligand-independent ER activity that results in tumor growth and to partial resistance to aromatase inhibitors and antiestrogen therapy (Jeselsohn et al. 2015, Jeselsohn et al. 2017). The list of ER $\alpha$ mutations may be found e.g. in the review of Alluri et al. (2014).

It is evident that simple ER mutations could not explain development of acquired estrogen resistance. Therefore new concepts of endocrine resistance involving molecular signaling have been searched (Clarke et al. 2015). Of a particular importance is the role of coactivators/co-regulators. In addition, so far putative membrane receptors for estrogens were found, acting through G-proteins (Soltysik and Czekaj 2013), which may further influence molecular signaling and lead to estrogen resistance.

In brief, the following events may take part in the ER signaling: 1) Phosphorylation of ER $\alpha$ through various kinase signaling pathways (Anbalagan and Rowan 2015). It concerns also already mentioned membrane receptors (Girault et al. 2006). 2) Interaction of ER with multifunctional, transcription factors, already referred in connection with GR signaling (Cain and Cidlowski 2015). A typical example is activation protein AP-1 (Pearce and Jordan 2004). 3) Post-translational modifications of ER (Anbalagan et al. 2012). 4) Alternative ER splicing (Barone et al. 2010). 5) In spite of more than 15 years of research, not fully explained remains the role of ER $\beta$ (Haldosén et al. 2014, Tan et al. 2016). 6) Very little is known so far about eventual down regulation of ER, similar to GR (Nardone et al. 2015). This brief list is far not complete; the theme is live and shows the ways of the further research.

\section{Conclusion}

In the review the main events are briefly outlined, accounting for steroid hormone resistance. We have focused on the main classes of steroid hormones used in therapy, first of all on glucocorticoids. We attempted to provide information of the multifarious molecular mechanisms staying behind the phenomenon steroid resistance, either genetically conditioned or acquired. We hope that so far scattered findings will compose into a mosaic, enabling not only to understand the molecular causes of the resistance, but also an efficient therapy of severe diseases.

\section{Conflict of Interest}

There is no conflict of interest.

\section{Acknowledgements}

This work was supported by the project $\mathrm{MH} \mathrm{CZ} \mathrm{-} \mathrm{DRO}$ (Institute of Endocrinology - EÚ, 00023761) and by the MEYS CR (OP RDE, Excellent research - ENDO.CZ).

\begin{abstract}
Abbreviations
11ß-HSD1, $11 \beta$-hydroxysteroid edehydrogenase Type 1; $\mathrm{ACTH}$, adrenocorticotropic hormone; AP-1, activation protein 1; $\mathrm{ARE}$, androgen receptor; $\mathrm{CAG}$, cytosine, adenine, guanine trinucleotide; CAIS, complete androgen insensitivity syndrome; $\mathrm{CRH}$, corticotropin releasing hormone, corticoliberin; CRPC, castration resistant prostate cancer; DHEA, dehydroepiandrosterone; ER, estrogen receptor; GC, glucocorticoid; GR, glucocorticoid receptor; GRE, glucocorticoid responsive element $(\mathrm{nGRE}=$ negative); hsp, heat shock protein; hGR, human glucocorticoid receptor; HPA, hypothalamopituitary-adrenal axis; HRE, hormone responsive element; MAIS, mild androgen insensitivity syndrome; NF-אB, nuclear factor kappa B; PAIS, partial androgen insensitivity syndrome; polyQ, polyglutamine; SBMA, spinal and bulbar muscular atrophy.
\end{abstract}

\section{References}

ALLURI PG, SPEERS C, CHINNAIYAN AM: Estrogen receptor mutations and their role in breast cancer progression. Breast Cancer Res 16: 494, 2014.

ANBALAGAN M, ROWAN BG: Estrogen receptor alpha phosphorylation and its functional impact in human breast cancer. Mol Cell Endocrinol 418: 264-272, 2015. 
ANBALAGAN M, HUDERSON B, MURPHY L, ROWAN BG: Post-translational modifications of nuclear receptors and human disease. Nucl Recept Signal 10: e001, 2012.

ANTONARAKIS ES, ARMSTRONG AJ, DEHM SM, LUO J: Androgen receptor variant-driven prostate cancer: clinical implications and therapeutic targeting. Prostate Cancer Prostatic Dis 19: 231-241, 2016.

BARONE I, BRUSCO L, FUQUA SA: Estrogen receptor mutations and changes in downstream gene expression and signaling. Clin Cancer Res 16: 2702-2708, 2010.

BOUDADI K, ANTONARAKIS ES: Resistance to novel antiandrogen therapies in metastatic castration-resistant prostate cancer. Clin Med Insights Oncol 10 (Suppl 1): 1-9, 2016.

BRINKMANN AO: Molecular basis of androgen insensitivity. Mol Cell Endocrinol 179: 105-109, 2001.

CAIN DW, CIDLOWSKI JA: Specificity and sensitivity of glucocorticoid signaling in health and disease. Best Pract Res Clin Endocrinol Metab 29: 545-556, 2015.

CHARMANDARI E: Primary generalized glucocorticoid resistance and hypersensitivity: the end-organ involvement in the stress response. Sci Signal 5: pt5, 2012.

CLARKE R, TYSON JJ, DIXON JM: Endocrine resistance in breast cancer - an overview and update. Mol Cell Endocrinol 418: 220-234, 2015.

COOPER MS, STEWART PM: 11Beta-hydroxysteroid dehydrogenase type 1 and its role in the hypothalamuspituitary-adrenal axis, metabolic syndrome, and inflammation. J Clin Endocrinol Metab 94: 4645-4654, 2009.

CULIG Z, SANTER FR: Androgen receptor co-activators in the regulation of cellular events in prostate cancer. World $J$ Urol 30: 297-302, 2012.

FISCHBECK KH: Spinal and bulbar muscular atrophy overview. J Mol Neurosci 58: 317-320, 2016.

GALON J, FRANCHIMONT D, HIROI N, FREY G, BOETTNER A, EHRHART-BORNSTEIN M, O'SHEA JJ, CHROUSOS GP, BORNSTEIN SR: Gene profiling reveals unknown enhancing and suppressive actions of glucocorticoids on immune cells. FASEB J 16: 61-71, 2002.

GIRAULT I, BIÈCHE I, LIDEREAU R: Role of estrogen receptor alpha transcriptional coregulators in tamoxifen resistance in breast cancer. Maturitas 54: 342-351, 2006.

HALDOSÉN LA, ZHAO C, DAHLMAN-WRIGHT K: Estrogen receptor beta in breast cancer. Mol Cell Endocrinol 382: 665-672, 2014.

HEEMERS HV, TINDALL DJ: Androgen receptor (AR) coregulators: a diversity of functions converging on and regulating the AR transcriptional complex. Endocr Rev 28: 778-808, 2007.

HEINLEIN CA, CHANG C: Androgen receptor (AR) coregulators: an overview. Endocr Rev 23: 175-200, 2002.

HENNEBERT O, PERNELLE C, FERROUD C, MORFIN R: 7alpha- and 7beta-hydroxy-epiandrosterone as substrates and inhibitors for the human 11beta-hydroxysteroid dehydrogenase type 1. J Steroid Biochem Mol Biol 105: 159-165, 2007.

HIORT O: Clinical and molecular aspects of androgen insensitivity. Endocr Dev 24: 33-40, 2013.

HUA G, GANTI KP, CHAMBON P: Glucocorticoid-induced tethered transrepression requires sumoylation of GR and formation of a SUMO-SMRT/NCoR1-HDAC3 repressing complex. Proc Natl Acad Sci U S A 113: E635-E643, 2016.

HUGHES IA, DAVIES JD, BUNCH TI, PASTERSKI V, MASTROYANNOPOULOU K, MACDOUGALL J: Androgen insensitivity syndrome. Lancet 380: 1419-1428, 2012.

JÄÄSKELÄINEN J: Molecular biology of androgen insensitivity. Mol Cell Endocrinol 352: 4-12, 2012.

JESELSOHN R, BUCHWALTER G, DE ANGELIS C, BROWN M, SCHIFF R: ESR1 mutations as a mechanism for acquired endocrine resistance in breast cancer. Nat Rev Clin Oncol 12: 573-583, 2015.

JESELSOHN R, DE ANGELIS C, BROWN M, SCHIFF R: The evolving role of the estrogen receptor mutations in endocrine therapy-resistant breast cancer. Curr Oncol Rep 19: 35, 2017.

KARANTANOS T, EVANS CP, TOMBAL B, THOMPSON TC, MONTIRONI R, ISAACS WB: Understanding the mechanisms of androgen deprivation resistance in prostate cancer at the molecular level. Eur Urol 67: 470-479, 2015.

KERDIVEL G, FLOURIOT G, PAKDEL F: Modulation of estrogen receptor alpha activity and expression during breast cancer progression. Vitam Horm 93: 1351-1360, 2013. 
KORYAKINA Y, TA HQ, GIOELI D: Androgen receptor phosphorylation: biological context and functional consequences. Endocr Relat Cancer 21: T131-T145, 2014.

LIANG Y, SONG MM, LIU SY, MA LL: Relationship between expression of glucocorticoid receptor isoforms and glucocorticoid resistance in immune thrombocytopenia. Hematology 21: 440-446, 2016.

LI X, HUANG J, YI P, BAMBARA RA, HILF R, MUYAN M: Single-chain estrogen receptors (ERs) reveal that the ERalpha/beta heterodimer emulates functions of the ERalpha dimer in genomic estrogen signaling pathways. Mol Cell Biol 24: 7681-7694, 2004.

LUCA F, MARANVILLE JC, RICHARDS AL, WITONSKY DB, STEPHENS M, Di RIENZO A: Genetic, functional and molecular features of glucocorticoid receptor binding. PLoS One 8: e61654, 2013.

MCPHAUL MJ: Androgen receptor mutations and androgen insensitivity. Mol Cell Endocrinol 198: 61-67, 2002.

MIFSUD KR, SAUNDERSON EA, SPIERS H, CARTER SD, TROLLOPE AF, MILL J, REUL JM: Rapid downregulation of glucocorticoid receptor gene expression in the dentate gyrus after acute stress in vivo: role of DNA methylation and micro-RNA activity. Neuroendocrinology 104: 157-169, 2017.

MONGAN NP, TADOKORO-CUCCARO R, BUNCH T, HUGHES IA: Androgen insensitivity syndrome. Best Pract Res Clin Endocrinol Metab 29: 569-580, 2015.

NAKAZAWA M, ANTONARAKIS ES, LUO J: Androgen receptor splice variants in the era of enzalutamide and abiraterone. Horm Cancer 5: 265-273, 2014.

NARDONE A, DE ANGELIS C, TRIVEDI MV, OSBORNE CK, SCHIFF R: The changing role of ER in endocrine resistance. Breast 24 (Suppl 2): S60-S66, 2015.

NICOLAIDES NC, CHARMANDARI E: Chrousos syndrome: from molecular pathogenesis to therapeutic management. Eur J Clin Invest 45: 504-514, 2015.

NICOLAIDES NC, ROBERTS ML, KINO T, BRAATVEDT G, HURT DE, KATSANTONI E, SERTEDAKI A, CHROUSOS GP, CHARMANDARI E: A novel point mutation of the human glucocorticoid receptor gene causes primary generalized glucocorticoid resistance through impaired interaction with the LXXLL motif of the p160 coactivators dissociation of the transactivating and transreppressive activities. $J$ Clin Endocrinol Metab 99: E902-E907, 2014.

NICOLAIDES NC, LAMPROKOSTOPOULOU A, SERTEDAKI A, CHARMANDARI E: Recent advances in the molecular mechanisms causing primary generalized glucocorticoid resistance. Hormones (Athens) 15: 23-34, $2016 \mathrm{a}$.

NICOLAIDES NC, SKYRLA E, VLACHAKIS D, PSARRA AM, MOUTSATSOU P, SERTEDAKI A, KOSSIDA S, CHARMANDARI E: Functional characterization of the hGRaT556I causing Chrousos syndrome. Eur J Clin Invest 46: 42-49, $2016 \mathrm{~b}$.

ORR CR, MONTIE HL, LIU Y, BOLZONI E, JENKINS SC, WILSON EM, JOSEPH JD, MCDONNELL DP, MERRY DE: An interdomain interaction of the androgen receptor is required for its aggregation and toxicity in spinal and bulbar muscular atrophy. J Biol Chem 285: 35567-35577, 2010.

PEARCE ST, JORDAN VC: The biological role of estrogen receptors alpha and beta in cancer. Crit Rev Oncol Hematol 50: 3-22, 2004.

PENNUTO M, BASSO M: In vitro and in vivo modeling of spinal and bulbar muscular atrophy. $J$ Mol Neurosci 58: 365-373, 2016.

POLETTI A, NEGRI-CESI P, MARTINI L: Reflections on the diseases linked to mutations of the androgen receptor. Endocrine 28: 243-262, 2005.

QUERIN G, SORARÙ G, PRADAT PF: Kennedy disease (X-linked recessive bulbospinal neuronopathy): A comprehensive review from pathophysiology to therapy. Rev Neurol (Paris) 173: 326-337, 2017.

QUINN M, RAMAMOORTHY S, CIDLOWSKI JA: Sexually dimorphic actions of glucocorticoids: beyond chromosomes and sex hormones. Ann N Y Acad Sci 1317: 1-6, 2014.

SCHAAF MJ, CIDLOWSKI JA: Molecular mechanisms of glucocorticoid action and resistance. J Steroid Biochem Mol Biol 83: 37-48, 2002.

SLOMINSKI AT, MANNA PR, TUCKEY RC: On the role of skin in the regulation of local and systemic steroidogenic activities. Steroids 103: 72-88, 2015. 
SOLTYSIK K, CZEKAJ P: Membrane estrogen receptors - is it an alternative way of estrogen action? J Physiol Pharmacol 64: 129-142, 2013.

TAN MH, LI J, XU HE, MELCHER K, YONG EL: Androgen receptor: structure, role in prostate cancer and drug discovery. Acta Pharmacol Sin 36: 3-23, 2015.

TAN W, LI Q, CHEN K, SU F, SONG E, GONG C: Estrogen receptor beta as a prognostic factor in breast cancer patients: a systematic review and meta-analysis. Oncotarget 7: 10373-10385, 2016.

THOMAS C, GUSTAFSSON JÅ: Estrogen receptor mutations and functional consequences for breast cancer. Trends Endocrinol Metab 26: 467-476, 2015.

TRAPMAN J, KLAASSEN P, KUIPER GG, VAN DER KORPUT JA, FABER PW, VAN ROOIJ HC, GEURST VAN KESSEL A, VOORHORST MM, MULDER E, BRINKMANN AO: Cloning, structure and expression of a cDNA encoding the human androgen receptor. Biochem Biophys Res Commun 153: 241-248, 1988.

WADOSKY KM, KOOCHEKPOUR S: Molecular mechanisms underlying resistance to androgen deprivation therapy in prostate cancer. Oncotarget 7: 64447-64470, 2016.

WALTERING KK, URBANUCCI A, VISAKORPI T: Androgen receptor (AR) aberrations in castration-resistant prostate cancer. Mol Cell Endocrinol 360: 38-43, 2012.

ZARIF JC, MIRANTI CK: The importance of non-nuclear AR signaling in prostate cancer progression and therapeutic resistance. Cell Signal 28: 348-356, 2016.

ZHOU J, CIDLOWSKI JA: The human glucocorticoid receptor: one gene, multiple proteins and diverse responses. Steroids 70: 407-417, 2005. 